\title{
Scanning Probe Microscope
}

National Cancer Institute

\section{Source}

National Cancer Institute. Scanning Probe Microscope. NCI Thesaurus. Code C78803.

A microscope that forms images of surfaces using a physical probe that scans the specimen and records the probe-surface interaction as a function of position. 